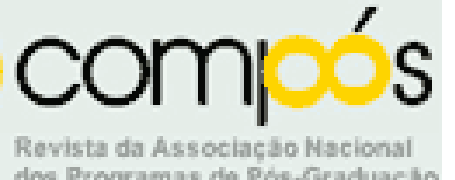

dos Programas de Pós-Craduaço

Este artigo foi publicado na edição 1, em dezembro de 2004, da revista eletrônica e-compós: http://www.compos.org.br/e-compos

\title{
A IDENTIDADE JORNALÍSTICA NO BRASIL: ALGUMAS QUESTÕES TEÓRICAS E METODOLÓGICAS ${ }^{1}$
}

\author{
Afonso de Albuquerque
}

UFF

Nessa exposição, pretendo discutir algumas questões relativas ao processo de construção da identidade jornalística no Brasil. Minha atenção estará focada para os seguintes aspectos: 1) o tratamento que o tema tem recebido no âmbito do Programa de Pós-Graduação em Comunicação da UFF; 2) considerações gerais a partir de minha própria experiência pregressa no tratamento do tema; 3) discussão da importância desse enfoque acerca do jornalismo, tendo em vista o caso do Conselho Federal de Jornalismo; 4) observações quanto aos problemas teóricos e metodológicos que se apresentam hoje neste tipo de investigação.

\section{A pesquisa sobre o jornalismo no Programa em Comunicação da UFF}

O estudo do jornalismo tem merecido uma atenção sistemática do Programa em Comunicação da UFF desde a sua origem. O tema foi objeto de projetos de pesquisa financiados pelo CNPq de dois docentes do Programa (Marialva Carlos Barbosa e Afonso de Albuquerque). Além disso, uma parcela substancial das dissertações do Programa - 20 de um total de 70 defendidas até setembro deste ano - teve no jornalismo o seu tema central.

\footnotetext{
${ }^{1}$ Versão apresentada no IV INTERPROGRAMAS DA COMPÓS, aberta a nova versão (20 a 25 laudas) para edição final.
} 
Desde o princípio, o Programa de Pós Graduação em Comunicação da UFF tem valorizado investigações que problematizem questões particulares do jornalismo com base na análise empírica de fenômenos específicos. Assim, por

exemplo, o problema da autoridade jornalística, considerado em relação à autoridade específica das instâncias governamentais foi analisado em dissertações sobre o programa "Linha Direta" (tendo em vista como, nele, o jornalismo se apropria do papel de julgar); sobre a comparação entre o modo como o discurso judiciário e o discurso jornalístico produziram verdades acerca do assassinato de Daniela Perez; sobre o modo como os jornalistas buscam legitimar o seu papel de porta-vozes da população junto às autoridades locais (no caso do RJTV) ou atuaram como mobilizadores da opinião pública em favor do Plano Cruzado, em nome dos mais altos interesses nacionais. Tais exemplos não são representativos da diversidade de temas e abordagens que se fazem presentes em relação ao fenômeno do jornalismo no Programa em Comunicação da UFF, mas, em seu conjunto, permitem demonstrar como a análise de objetos aparentemente tão distintos mantém um diálogo efetivo no âmbito de uma mesma agenda de pesquisa.

\section{A identidade jornalística no Brasil: etapas de um percurso investigativo}

Há aproximadamente dez anos venho me dedicando ao estudo de fenômenos referentes ao jornalismo, sendo que nos últimos cinco tenho considerado questões relativas à identidade jornalística no Brasil. Até o presente momento, este esforço se materializou em quatro produtos, nos quais busquei dar conta de aspectos tão distintos quanto complementares do problema.

O primeiro desses produtos - o artigo "Um outro quarto poder: imprensa e responsabilidade política no Brasil” - buscou estabelecer um marco geral para a análise do problema da identidade jornalística em nosso país, tendo em vista o modo como ela se define em referência ao modelo americano de jornalismo. $\mathrm{O}$ que motivou a análise foi a constatação de que as comparações então disponíveis (por exemplo, Jobim, 1992 e Silva, 1991) apresentavam um caráter fortemente normativo e buscavam dar conta das razões do incompleto sucesso 
(na melhor das hipóteses) ou fracasso (na pior delas) da adoção do modelo de jornalismo americano no Brasil. Análises sobre a adoção (mais ou menos bem sucedida) do modelo americano de jornalismo ou dos fatores que a restringem têm sido realizadas acerca de diversos outros países (ver, por exemplo, Manzella, 2000; Hallin \& Papathanassopoulos, 2002; Tettey, 2001). Todas elas apresentam dois inconvenientes. Em primeiro lugar elas atribuem, de maneira pouco crítica, um valor universal ao modelo americano de jornalismo (na verdade o governo e a imprensa americana buscaram ativamente assumir este papel a partir do final da Segunda Grande Guerra, como o demostra Blanchard, 1986). Em segundo lugar, elas parecem supor que valores e padrões de comportamento culturais poderiam ser simplesmente transferidos de uma cultura para outra.

Alternativamente a essas perspectivas, minha análise procurou enfocar a adaptação (antes que a adoção) do modelo de jornalismo americano no Brasil. Adaptar significa aqui reler, reformatar um modelo estrangeiro de modo que ele atenda às exigências da cultura que o "importa". No caso específico do meu artigo, o foco da análise recaiu sobre a noção recorrente de que o jornalismo constitui um "quarto poder" do governo, cujas origens remetem ao jornalismo anglo-americano. Defendi o argumento de que, historicamente, desenvolveu-se no país uma outra tradição de quarto poder, a do Poder Moderador, que embora tenha oficialmente durado apenas durante o período do Império, permaneceu bastante influente ao longo de toda a história republicana.

A tradição do "quarto poder" americana se baseia no modelo conhecido como "checks and balances", no qual a divisão e a interdependência dos poderes (através de um sistema de pesos e contrapesos) são consideradas como a melhor garantia da defesa dos direitos dos cidadãos, em oposição à ameaça da tirania. Neste sentido, o exercício do "quarto poder" pelo jornalismo estaria ligado ao compromisso deste com a Constituição e com o sistema de três poderes entendido como um todo. A tradição do Poder Moderador faz uma leitura diferente do problema da divisão de poderes: por um lado, ela é considerada como um requisito obrigatório para definir uma sociedade como politicamente civilizada; por outro, ela é considerada um estorvo, dado que a divisão de poderes (entendidos como poderes independentes, antes que interdependentes) é considerada como uma ameaça potencial à governabilidade e à ordem social. 
Cabe ao Poder Moderador intervir nesses conflitos para restaurar a ordem. Durante o período republicano, algumas instituições reivindicaram ou foram reconhecidas como dotadas da autoridade necessária para representarem este papel. No período de 1946 a 1964, as Forças Armadas desempenharam a função de guardiãs últimas da Constituição, papel que foi substituído a partir do golpe militar pelo de executivo forte. Findo o período militar e renovados os compromissos com a ordem democrática, permaneceram as desconfianças quanto à efetividade do sistema de divisão de poderes e a noção de que é necessária a atuação de forças externas para garantir o equilíbrio do sistema. Nenhuma instituição foi capaz de monopolizar o exercício deste papel; algumas instituições têm, contudo, reivindicado exercer este papel, dentre elas a imprensa (o Ministério Público é outra instituição que reivindica a mesma coisa). No artigo, argumentei que a imprensa brasileira recorre ao discurso americano do quarto poder para justificar um tipo de pretensão totalmente diferente.

O artigo em questão buscou formular uma hipótese genérica acerca da identidade jornalística no Brasil, deixando a tarefa da condução de estudos específicos sobre o problema para os trabalhos seguintes. O primeiro deles, "Media criticism no Brasil: o Observatório da Imprensa" - escrito em co-autoria com Marco Roxo e João Martins, ambos mestres pelo Programa da UFF - teve como objetivo fundamental analisar o debate relativo à identidade jornalística, tal como travado na homepage do Observatório da Imprensa. A premissa básica era de que o Observatório da Imprensa poderia ser considerado como uma arena na qual os jornalistas poderiam disputar e negociar, entre si mesmo e com outros agentes, questões relativas à sua identidade profissional. $\mathrm{O}$ fato de se tratar de uma homepage permite ao Observatório da Imprensa promover um debate em âmbito nacional, o que faria dele um objeto particularmente interessante para testar as hipóteses elaboradas no artigo anterior.

Logo, porém, um problema nos chamou a atenção: o Observatório da Imprensa define o seu lugar no debate acerca do jornalismo de maneira fundamentalmente dúbia, visto que ele desempenha simultaneamente os papéis de arena (o fórum no qual o debate se dá) e agente participante do debate (dotado de um papel missionário na defesa de um jornalismo correto). Para além das questões éticas aí implicadas, esta dubiedade trazia problemas 
metodológicos importantes para a nossa análise. O desempenho deste duplo papel pelo Observatório da Imprensa fazia dele um superparticipante do debate. Afinal, de todos os participantes, o Observatório da Imprensa é o único que dispõe de poderes editoriais, o que significa que ele pode contextualizar, destacar ou minimizar os argumentos dos diversos participantes (através do uso de recursos como chamadas para textos de alguns autores e não outros, a classificação dos textos em seções mais ou menos “quentes", a ordem de apresentação dos textos, para não mencionar o simples processo de inclusão/exclusão de textos do debate). Em face da importância dessa dimensão "editorial" como constitutiva do debate no Observatório da Imprensa, a análise do debate em torno da identidade profissional jornalística mostrou ser um problema mais complexo do que parecia a princípio.

A estratégia seguinte foi a de buscar analisar o debate em torno da identidade profissional dos jornalistas tendo por base questões específicas e intensas o suficiente para mobilizar jornalistas e outros agentes sociais. Em coautoria com Rafael Fortes, igualmente mestre pelo Programa em Comunicação da UFF, tive a oportunidade de produzir dois textos, os quais versavam, respectivamente, sobre o debate que cercou o lançamento do livro Notícias do Planalto, de Mario Sergio Conti, sobre as relações entre imprensa e poder no período que vai da campanha presidencial de 1989, da qual Collor de Mello saiu vitorioso, ao seu impeachment, em 1992; e o debate sobre a exigência de diploma específico para o exercício do jornalismo.

O primeiro deles analisou questões relativas aos modos de construção da memória da atuação da imprensa no período de 1989 a 1992 e sua apropriação no que concerne à legitimação de agentes e/ou práticas no presente. Deste ponto de vista, interessou-nos investigar quais foram as estratégias de convergência - através das quais os jornalistas sublinham traços de sua identidade comum frente a outros agentes interpretativos - e as estratégias de confronto - através das quais setores dos jornalistas disputam entre si a autoridade interpretativa - utilizadas no debate. A análise considerou um universo bastante diversificado de discursos veiculados pela imprensa bem como outros que constaram de debate realizado no âmbito do Observatório da Imprensa. Esses comentários foram analisados tendo em vista duas rubricas principais: 1) observações sobre o livro - por sua vez subdivididas em 
comentários sobre o conteúdo do livro; sobre o autor do livro; sobre aspectos formais e metodológicos do livro e sobre o impacto do livro junto ao público (e aos leitores jornalistas em particular); 2) observações mais genéricas acerca do comportamento da imprensa no passado e no presente.

$\mathrm{O}$ artigo identificou algumas estratégias de convergência recorrentes nos depoimentos. O fato de o autor de Notícias do Planalto ser jornalista e o formato de "grande reportagem" do livro foram fatores recorrentemente elogiados. Observa-se, igualmente, uma tendência dos comentários de focar a sua atenção em episódios pontuais de má-conduta profissional, tais como a edição do último debate entre Collor e Lula em 1989 e o episódio de tentativa de suborno que Conti atribui ao jornalista (na verdade Conti se refere a ele como ex-jornalista) Mário Alberto de Almeida. Além disso, um conjunto significativo de comentários extrai do livro uma mesma conclusão: a imprensa errou muito no tratamento que deu a Collor na campanha presidencial e nos primeiros anos do governo, mas extraiu dos erros lições que a preparam para exercer de modo mais consciente o seu papel daqui para diante. Há, igualmente, padrões identificáveis no que concerne às estratégias de confronto. Um eixo de disputa envolveu a responsabilização pelos erros da cobertura: os culpados pelos erros foram os patrões ou os jornalistas? O outro eixo concerne aos méritos das denúncias que abasteceram o processo de impeachment contra Collor. Freqüentemente essa disputa opõe veículos do mainstream a outros caracterizados, ao menos em termos comparativos, como mais "alternativos" (no caso, as revistas IstoÉ e Carta Capital). Outra disputa opõe veículos do próprio mainstream (Folha de S. Paulo e Veja, por exemplo).

$\mathrm{O}$ artigo revelou ainda que o conceito de objetividade constitui um importante referencial para o debate em torno da identidade jornalística, embora as referências a ela sejam freqüentemente marcadas por um certo desconforto. No mais das vezes, a referência é feita no sentido de sublinhar o valor da objetividade como princípio mas sua insuficiente presença (ou efetiva ausência).

O segundo texto, apresentado no XXVII Congresso Brasileiro de Ciências da Comunicação, realizado este ano, teve como objeto o debate travado em torno da exigência do diploma específico para o exercício profissional do jornalismo, a partir da decisão judicial da juíza Carla Abrantkoski Rister, que 
suspendeu provisoriamente tal exigência. Para os fins da nossa análise, este debate foi considerado como parte integrante de um debate mais amplo, sobre o modo como os jornalistas negociam, interna e externamente, os limites da sua competência profissional.

Neste sentido, o texto percorreu dois eixos analíticos complementares.O primeiro analisou o tema do diploma tendo em vista a negociação das fronteiras internas do jornalismo. Os argumentos foram considerados tendo em vista quatro dimensões fundamentais, relativas às razões de ordem técnica, ética, econômica e política que a justificariam ou não a exigência do diploma específico para o exercício do jornalismo. O outro eixo da análise teve como tema a definição das fronteiras externas do jornalismo, tendo em vista as relações que este estabelece com a universidade (a instituição que fornece o diploma), a comparação entre o jornalismo e outras atividades profissionais e a situação da profissão jornalística (e o papel que a exigência do diploma desempenha nela) no Brasil e em outros países. Em síntese, a análise revelou a existência de um nível muito baixo de acordo entre os jornalistas, não apenas em relação ao problema do diploma específico, mas de outras questões fundamentais acerca do jornalismo.

A conclusão do artigo é que tal nível de desacordo entre os jornalistas pode ser, em parte, uma conseqüência do próprio processo que estabeleceu a exigência do diploma específico para o exercício da profissão, ao menos nas condições em que ele se deu no Brasil. Dois aspectos do problema merecem ser mencionados. Em primeiro lugar, a exigência foi estabelecida durante a época mais sombria do Regime Militar, em condições tremendamente inibidoras para o debate público sobre qualquer assunto, portanto. Em segundo lugar, a exigência do diploma específico estabeleceu um critério essencialmente formal/burocrático para definir quem é jornalista, o que desestimulou um debate mais aprofundado sobre a natureza concreta do jornalismo como atividade profissional. Deste ponto de vista, a decisão da juíza Carla Rister contestando a obrigatoriedade do diploma teve o mérito de abrir caminho para um vigoroso debate entre os jornalistas, acerca da sua identidade profissional.

\section{Os jornalistas diante de um dilema: o Conselho Federal de Jornalismo}


O problema da falta de um acordo mínimo dos jornalistas brasileiros em torno das questões fundamentais de sua profissão voltou a se fazer evidente mais recentemente, diante do anúncio da criação de um Conselho Federal de Jornalismo (CFJ) pelo governo Lula. A proposta foi saudada pela Federação Nacional dos Jornalistas (FENAJ) como uma conquista histórica dos jornalistas e da sociedade, e condenada pela maioria das empresas jornalísticas como um atentado contra a liberdade de expressão no país (os defensores do projeto responderam a esta acusação sustentando que a oposição ao projeto escondia uma defesa da liberdade de empresa, antes que da liberdade de imprensa). Muitos jornalistas não evidentemente vinculados à FENAJ ou aos interesses das empresas se posicionaram contra ou a favor do projeto, alegando variadas razões. Alguns o fizeram de maneira mais impetuosa, atacando tanto os argumentos quanto os adversários, enquanto outros escolheram lidar com o problema de maneira mais ponderada.

Diante de tal profusão de manifestações sobre a relevância ou a inaceitabilidade do CFJ, não cabe a este trabalho a tarefa de apresentar mais um argumento ao debate. O problema que me interessa é outro, que creio mais profundo. Acredito que um dos fatores que tem tornado tão intenso o debate sobre o CFJ é justamente a ausência de um amplo acordo sobre o conjunto de princípios que permitam definir quem é o jornalista e como ele deve pautar o seu comportamento. Um exemplo bastante eloqüente é a polêmica recente acerca do status de jornalista do assessor de imprensa - seria ele um jornalista ou não? - travada no âmbito do debate sobre o CFJ.

Em termos bastante simplificados, acreditamos poder identificar, por detrás do debate, a disputa entre dois mitos fundadores do jornalismo brasileiro "moderno", aos quais, por uma questão de comodidade, passo a chamar de "mito dos anos cinqüenta" e "mito dos anos oitenta". Ambos têm nos anos 1950 e nos anos 1980 referenciais discursivos fundamentais, mas eles avaliam o significado desses dois marcos de maneira inteiramente diferente.

O "mito dos anos cinqüenta" sustenta que o jornalismo brasileiro moderno foi forjado na década de 1950, momento decisivo da implantação das práticas e valores que, ainda hoje, definem o "bom jornalismo": novas práticas textuais e a valorização da reportagem teriam permitido ao jornalista se 
profissionalizar, distinguindo-se do tipo de boêmio e literato que, até então, imperava nas redações. Os anos cinqüenta marcam portanto, o início de um processo de racionalização, através do qual o jornalismo brasileiro se põe no rumo. Em um argumento bastante semelhante ao que Adorno e Horkheimer desenvolvem em sua "Dialética do Esclarecimento", o "mito dos anos cinqüenta" identifica nos anos oitenta um momento onde a lógica de mercado (racionalidade instrumental) passa a predominar no jornalismo, em detrimento do seu compromisso com o interesse público (sua missão libertadora).

No "mito dos anos oitenta", os anos cinqüenta também são valorizados, mas como precursores das verdadeiras transformações que somente se completariam três décadas depois. Nessa via de interpretação, os anos cinqüenta apresentaram ao Brasil um modelo moderno de jornalismo, mas naquela época não havia condições materiais que permitissem a sua efetiva implementação. Diante da dependência econômica dos veículos noticiosos em relação ao governo e das forças partidárias, a objetividade jornalística não poderia ser outra coisa que não um ideal distante. Sob este prisma, os anos oitenta apresentam um momento decisivo para a consolidação do jornalismo. Solidamente estruturadas como empresas, as organizações jornalísticas passaram a dispor de condições mais efetivas para sustentar a sua independência frente aos diversos agentes políticos. No "mito dos anos oitenta", a estruturação da imprensa em termos radicalmente capitalistas não se opõe ao seu compromisso com o interesse público; é, ao contrário, a condição fundamental desse compromisso.

Os dois modelos têm sido adotados - por grupos diferentes - como explicações auto-evidentes acerca do desenvolvimento do jornalismo brasileiro. Acredito, porém, que, para além do seu efetivo poder explicativo, o principal valor desses modelos é o de servir como referenciais para um processo de construção de memória e identidades coletivas por diferentes grupos de jornalistas. É por isso, aliás, que me refiro aos dois modelos explicativos como "mitos", no sentido que Sorel dá ao termo: idéias-força, “meios de agir sobre o presente". Se o "mito dos anos cinqüenta" legitima um discurso que tem no profissional o ator principal do jornalismo, no "mito dos anos oitenta", este papel é destinado às empresas jornalísticas. Do ponto de vista do seu valor analítico, porém, esses modelos apresentam muitos limites. Por exemplo, eles 
não dizem quase nada sobre o jornalismo brasileiro anterior à década de 1950, e quando o fazem, muitas vezes o retratam de maneira preconceituosa, nos termos de uma idade das trevas do jornalismo brasileiro, na qual jornalistas "boêmios", devotos de práticas bárbaras e inexplicáveis - como por exemplo o "nariz de cera" - imperavam.

Esses mitos desempenham um papel importante no sentido de municiar os argumentos dos antagonistas em questões polêmicas acerca do jornalismo (tais como os problemas do CFJ e do diploma), mas o seu potencial para ampliar o conhecimento relativo ao desenvolvimento do jornalismo no Brasil é pouco significativo. Os dois modelos destacam a ação inovadora de um conjunto de agentes que contribuíram para que o jornalismo brasileiro tivesse a face que apresenta atualmente, mas o fazem às custas do apagamento daquilo que existia antes, bem como do papel que foi desempenhado por outros agentes. Não basta reconhecer que os anos cinqüenta e os anos oitenta foram marcos importantes no processo de transformação do jornalismo brasileiro; para entender apropriadamente o significado e relativizar a dimensão dessas transformações é necessário ter uma melhor compreensão do que existia antes dessas transformações, bem como dos traços do jornalismo brasileiro que sobreviveram a elas.

O entendimento mais aprofundado das circunstâncias particulares que têm cercado o desenvolvimento do jornalismo brasileiro é um pré-requisito para que se possa definir os termos de um acordo mais amplo em torno da ética jornalística. É preciso esclarecer, neste sentido, que a existência de um Código de Ética da profissão não implica necessariamente em um sólido acordo em torno das questões fundamentais da ética jornalística. O que está em questão aqui não é a referência a princípios orientadores gerais da prática jornalística, mas a sua aplicação concreta a situações e controvérsias práticas (cf. Ettema \& Glasser, 1998). Na ausência de um tal acordo, uma instância como o CFJ encarregada do papel de "orientar, disciplinar e fiscalizar o exercício da profissão de jornalista e da atividade de jornalismo" e de "zelar pela fiel observância dos princípios de ética e disciplina" - poderá até dispor de poder, mas dificilmente terá autoridade (cf. Sennett, 2001). Acredito que, ao aprofundar o conhecimento existente sobre as particularidades que a prática do 
jornalismo assumiu no Brasil, a pesquisa acadêmica poderá dar uma expressiva contribuição neste sentido.

\section{A identidade jornalística e a pesquisa acadêmica: problemas e perspectivas}

A pesquisa acerca do jornalismo se desenvolveu consideravelmente no Brasil nos últimos anos, tanto do ponto de vista quantitativo quanto do qualitativo. Tal crescimento não se deu, contudo, de maneira homogênea. Alguns enfoques sobre o assunto se desenvolveram muito mais do que outros, e entre aqueles que menos evoluíram encontra-se a análise dos fatores históricos e culturais que têm contribuído para a formação da identidade jornalística no Brasil. Uma parcela considerável da produção bibliográfica disponível tem tomado o jornalismo como um fenômeno universal, a-histórico, pouco sujeito às influências de ambientes culturais específicos. Fala-se em uma teoria do jornalismo ou no jornalismo como forma de conhecimento, como se o jornalismo significasse a mesma coisa ou implicasse no mesmo conjunto de valores e práticas em todas as épocas e em toda parte. O que esta tradição chama pura e simplesmente de jornalismo corresponde na verdade a um modelo de jornalismo, originário dos Estados Unidos, tal como interpretado no Brasil. E, como o nosso exemplo relativo aos mitos dos anos cinqüenta e oitenta o demonstram, o modelo americano é interpretado de maneiras muito distintas no Brasil. Em outras palavras, as análises correntes acerca do jornalismo freqüentemente naturalizam aquilo que é um produto de circunstâncias culturais e históricas bastante particulares.

Um segundo problema, ainda mais importante, diz respeito às dificuldades que a análise acadêmica encontra para legitimar o seu lugar enquanto instância interpretativa autônoma diante dos agentes dos campos profissional e empresarial do jornalismo. O problema se torna ainda maior quando se considera o esforço de agentes de ambos os campos para utilizar a universidade como parte de uma estratégia de legitimação dos seus próprios pontos de vista. No plano institucional, um exemplo dessa estratégia passa pelas cátedras. O curso de jornalismo da Universidade Federal de Santa Catarina (UFSC), por exemplo, firmou acordos neste sentido com a FENAJ e, no outro 
extremo da escala ideológica, com a Rede Brasil Sul (RBS). O jornal Folha de $S$. Paulo, por outro lado, firmou a Cátedra de Jornalismo Octavio Frias de Oliveira com a Faculdade de Comunicação Social do Centro Universitário Alcântara Machado (UniFiam-Faam).

Mais do que isso, os agentes envolvidos têm buscado ativamente moldar os próprios termos do discurso acadêmico acerca do jornalismo. O "mito dos anos cinqüenta” dá conta de um projeto de construção de memória muito bem sucedido neste sentido. O seguinte depoimento de Alberto Dines, uma figura de proa deste projeto, é bastante ilustrativo dessa estratégia:

"Hoje você tem os jornalistas românticos, os mais velhos que fizeram esse grande jornalismo dos anos 50, 60, 70, e você tem a garotada, que tá reinventando a roda. Então você tem duas tendências, se confrontando: o pessoal do mercado, a garotada, um copia o outro, um denuncia o outro, denuncia o que o outro denunciou, e ninguém faz um jornalismo mais denso, e você tem a geração mais velha que é extremamente crítica. Extremamente crítica. Naquela época (nos anos 50-60) isso não aconteceu. Por que? Porque o que a garotada estava fazendo - eu era da garotada - era muito respeitado pelos outros. (...) Não era porra louquice de inventar uma coisinha, uma maluquice que acabava no dia seguinte. Então, eu não senti nenhuma reação. Ao contrário. Vieram para o Jornal do Brasil Luiz Alberto Baía, Antônio Callado, Carlos Castello Branco. Todos os grandes talentos do jornalismo no Brasil estavam lá. E não havia dissidência porque aquilo ficou majoritário. Tanto que o Jornal do Brasil exportou o seu modelo para o Brasil inteiro (...) Quem eram os velhos daquela época? Não eram os jornalistas; chegavam lá e escreviam uma coisinha. Não eram jornalistas profissionais. Os velhos de hoje são pessoas que estão há 50 anos na profissão, fazendo reformas. Então, mudou a discussão ficaram evidentemente 2 pólos. Naquela época não tinham dois pólos” (apud Ribeiro, 2003: 288).

O sucesso dessa estratégia pode ser confirmado, em muitos aspectos, nos cursos de jornalismo atuais, não apenas no modo como eles contam a história do jornalismo, mas também em diversos aspectos do ensino das disciplinas técnicas. A idéia, por alguns defendida, de que a pesquisa e o ensino do 
jornalismo são tarefas que devem ser preferencialmente (ou exclusivamente, em uma versão mais radical) exercidas por docentes com experiência profissional no jornalismo é mais um exemplo no mesmo sentido.

Agentes ligados às empresas jornalísticas também têm procurado influenciar os termos do debate acadêmico, eventualmente com algum sucesso. A Folha de S. Paulo se destacou neste sentido. Livros como Mil Dias e $O$ Adiantado da Hora, ambos de Carlos Eduardo Lins da Silva, que conciliou o papel de professor universitário ao de editor da Folha, dão conta de iniciativas bastante influentes neste sentido. Certamente não é por acaso que o jornal tem sido freqüentemente tomado como $o$ modelo do projeto de modernização do jornalismo brasileiro que teve lugar nos anos oitenta. $\mathrm{O}$ recente livro acerca do Jornal Nacional, patrocinado pela Memória Globo é outra iniciativa que obedece aos mesmos propósitos.

Não se trata de condenar as iniciativas de profissionais e empresas no sentido de influenciar o debate acadêmico acerca do jornalismo; elas são legítimas. Trata-se, apenas, de reconhecer que os resultados produzidos por essas iniciativas não podem ser tomados como respostas plenamente satisfatórias para os problemas que se apresentam ao estudo do jornalismo, particularmente no que toca ao estudo de questões relativas à identidade jornalística. O papel que cabe à perspectiva acadêmica desempenhar deve se fazer no sentido de ampliar o conhecimento existente sobre o jornalismo, e isso implica necessariamente em dialogar com as interpretações correntes, tanto quanto em desafiá-las. Trata-se de um papel fundamental, ainda mais em um momento como o atual, no qual o debate em torno da identidade profissional ganhou uma importância fundamental para os jornalistas.

\section{Referências Bibliográficas}

Albuquerque, Afonso de (2000). Um outro Quarto Poder: imprensa e compromisso político no Brasil. Contracampo: Revista do Mestrado em Comunicação, Imagem e Informação n. 4, jan. p. 23-57.

Albuquerque, Afonso de; João Damasceno Martins Ladeira. \& Marco Antonio Roxo da Silva (2002). Media criticism no Brasil: o Observatório da Imprensa. Revista Brasileira de Ciências da Comunicação, vol. XXV, n 2, p. 166-189.

Albuquerque, Afonso de \& Rafael Fortes Soares (2004). Notícias de notícias: Notícias do Planalto, memória e autoridade jornalística. Comunicação \& Política, n.s., v. IX, n. 1: 135-169. 
Ettema, James S. and Theodore L. Glasser (1998) Custodians of Conscience: Investigative Journalism and Public Virtue. New York: Columbia University Press.

Hallin, Daniel C. \& Stylianos Papathanassopoulos (2002) Political Clientelism and the Media: Southern Europe and Latin America in Comparative Perspective. Media, Culture \& Society, 24 (2): 175-195.

Jobim, Danton (1992) O espírito do jornalismo. São Paulo: Edusp/Com-Arte.

Memória Globo (2004). Jornal Nacional: a notícia faz história. Rio de Janeiro: Jorge Zahar Editor.

Ribeiro, Ana Paula Goulart (2003). Memória de Jornalista: Um Estudo Sobre o Conceito de Objetividade nos Relatos dos Homens de Imprensa dos Anos 50. In Vera França; Maria Helena Weber; Raquel Paiva; Liv Sovik (org.). Estudos de Comunicação: XI Compós. Porto Alegre: Editora Sulina.

Sennett, Richard. (2001). Autoridade. Rio de Janeiro: Record.

Silva, Carlos Eduardo Lins da (1988). Mil dias: os bastidores da revolução em um grande jornal. São Paulo: Trajetória Cultural.

Silva, Carlos Eduardo Lins da (1991) O adiantado da hora: a influência americana sobre o jornalismo brasileiro. São Paulo: Summus.

Tettey, Wisdom J. (2001) The media and democratization in Africa: contributions, constraints and concerns of the private press. Media, Culture \& Society 23 (1): 5-31. 